\title{
NILAI PENDIDIKAN DALAM TANGON-TANGON MASYARAKAT KADAZANDUSUN
}

\author{
Florina Jumil \\ olinchukasey.oc@gmail.com \\ Norjietta Julita Taisin \\ jietta@fbk.upsi.edu.my \\ Universiti Pendidikan Sultan Idris
}

The Educational Values in Tangon-Tangon Kadazandusun Community

\begin{abstract}
ABSTRAK
Masyarakat Kadazandusun merupakan kaum peribumi asli terbesar di Sabah yang sungguh kaya dengan khazanah berbentuk sastera lisan. Tangon-tangon ataupun lebih dikenali sebagai cerita rakyat merupakan salah satu sastera lisan yang mempunyai fungsi universal kerana peranannya sebagai alat kawalan sosial dalam kehidupan seharian khasnya dalam mendidik anak-anak. Maka kajian ini diketengahkan untuk mengenal pasti nilai pendidikan yang terdapat dalam beberapa tangon-tangon Kadazandusun. Teori Pendekatan Moral M.Atar Semi (1993) dijadikan landasan utama manakala Teori Formalistik sebagai teori sokongan pengkaji. Pengaplikasian kaedah analisis teks 'Himpunan Cerita Kadazandusun' dan kajian kepustakaan juga telah digunakan. Kajian mendapati bahawa terdapat banyak nilai pendidikan yang terdapat dalam tangon-tangon yang mampu membentuk karakter seseorang pembaca terutama kanak-kanak. Implikasinya, kajian ini menjadi pemangkin dalam mendidik para pembaca berfikir lebih kritis dan kreatif.
\end{abstract}

Kata kunci: tangon-tangon; nilai pendidikan; teori pendekatan moral; teori formalistik; kaedah analisis teks

\begin{abstract}
Kadazandusun community is the largest indigenous ethnic groups in Sabah who are wealthy with oral literature such as Tangon-tangon. Tangon-tangon or better known as folktale has a universal function as a medium of educational material as it is an instrument of social control in everyday life. Accordingly, this research was done to identify the educational value in some selected tangon-tangon (folktale). The Moral Approach Theory by M.Atar Semi (1993) is the main foundation while the Formalistic Theory is used as the supporting theory. This research used textual analysis through 'Himpunan Cerita Kadazandusun' and library studies. The study found that there are a lot of educational values in tangon-tangon that are able to shape the character of a reader especially children. Thus, this study is a catalyst in educating readers to think more critically and creatively.
\end{abstract}

Keywords: Tangon-tangon; educational value; moral Theory; formalistictheory; textual analysis

\section{PENGENALAN}

Kaum Kadazandusun merupakan salah satu etnik peribumi yang menetap di Pantai Barat Sabah dan kawasan pedalaman sekitarnya, (bmpengurusan, 2010). Menurut Persatuan Kebudayaan Kadazandusun Sabah (KDCA) dan di dalam perlembagaannya, Kadazandusun merujuk kepada empat puluh etnik seperti yang berikut: Bonggi, Lingkabau, Nabai, Tatana, Bundu, Liwan, Paitan, Tangara, Dumpas, Lobu, Pingas, Tidong, Gana, Lotud, Rumanau, Tindal, Garo, Lundayo, Rungus, Tobilung, Idaan, Makiang, Sinobu, Tolinting, Kadayan, Malapi, Sinorupu, Tombonuo, Kimaragang, Mangkaak, Sonsogon, Tuhawon, Kolobuan, Minokok, Sukang, Tutung, Kuijau, Murut, Sungai, Bisaya (Gwen Queerin Majin, 2012). 
Jika melihat dalam aspek sejarah lisan dan cerita lagenda, teori kedatangan kaum Kadazandusun yang paling terkenal dan lebih diketahui umum ialah "teori nunuk ragang". Menurut teori ini, orang Kadazandusun yang bertaburan di pelbagai tempat di Sabah masa kini berasal dari Nunuk Ragang. Nunuk Ragang merupakan sebuah kawasan yang terletak di Daerah Ranau iaitu tempat yang boleh dikunjungi apabila melalui jalan Pekan Ranau menuju ke Telupid. Kawasan tersebut dikenali sebagai Tompios, Ranau pada masa kini (Sarim Hj. Mustajad, 2004: 11-20). Kehidupan mereka pada masa itu dipenuhi dengan semangat bersatu padu, mogitabang-tabang, mogiuhup-uhup, otoluod, obinsianan, orulan, otorini, ohinomod, aparu, onimot, obingupus, okupi, obintinong, obintumbayaan, obingkanggau, obinronok, otuyu, osuau, obingopi, mamantang, opori, obulun dan onitinginawo (Henry, 2002). Berdasarkan kehidupan kaum Kadazandusun yang penuh dengan nilai-nilai tersebut, maka kita dapat mengetahui bahawa cerita ini membawa mesej agar generasi masa kini menyedari bahawa kaum Kadazandusun datang dari tempat yang sama pada asalnya dan harus memartabatkan warisan budaya, kesenian serta keunikannya seperti kata Ernest Renant (1929):

Bangsa adalah kesatuan jiwa. Jiwa yang mengandung kehendak untuk bersatu, orang-orang merasa diri satu dan mahu bersatu. Apabila semua manusia yang hidup di dalamnya mempunyai kehendak untuk bersatu maka sudah merupakan satu bangsa.

Kaum kadazandusun memiliki pelbagai khazanah warisan sejak turun-temurun yang kaya dengan unsur nasihat dan hiburan serta mampu menjadi bahan didikan kepada generasi masa dahulu sehingga kini. Jika melihat kembali sejarah masyarakat zaman dahulu yang bersifat little tradition dan primitif, mereka masih belum mampu menguasai sistem tulisan dan membaca. Maka, tradisi lisan hanya diceritakan secara lisan dan sehingga kini kewujudan tradisi lisan masih kurang diperhatikan dan kurang didokumentasikan (Julita @ Norjietta Bt Taisin, 2014 \& Minah Sintian, 2015). Kesemua tradisi lisan ini dicipta dalam masyarakat tanpa diketahui penciptanya. Antaranya ialah sundait (teka-teki), sudawil, taalaala, boor, luntiou, kiaton, tududoi, taboi-aboi (pantun), tinggono (lagu kanak-kanak), sandalom, torilu, kingkiaton (nyanyian rakyat), rinait (mantera), tangon/susuyon (cerita rakyat) dan sebagainya. Terdapat juga tukadan (peribahasa) seperti siriban/haraban (kiasan) dan piagalan/poiradan (perumpamaan) yang memperlihatkan kebijaksanaan dan pemikiran yang mendalam oleh masyarakat Kadazandusun zaman dahulu (Minah Sintian, 2015).

\section{LATAR BELAKANG KAJIAN}

Dalam kajian ini, pengkaji memfokuskan kepada perbincangan mengenai cerita rakyat ataupun dikenali sebagai tangon-tangon oleh masyarakat Kadazandusun. Tangon-tangon merupakan cerita-cerita yang lahir, hidup dan berkembang secara turun-temurun dalam masyarakat tradisional sama ada masyarakat tersebut telah mengenal huruf atau belum, disebarkan secara lisan, mengandungi survival, bersifat anonim, serta disebarkan di antara kolektif tertentu dalam kurun waktu yang cukup lama (Sisyono, 2008). Cerita rakyat (tangon-tangon) juga mempunyai fungsi universal sebagai medium hiburan di samping menjadi bahan mengajar dan mendidik kerana ianya mempunyai peranan sebagai alat kawalan sosial dalam kehidupan seharian (Aripin, 1996). Pengkaji mengecilkan skop kajian dengan menumpukan kepada nilai pendidikan yang wujud melalui watak dan perwatakan serta jalan cerita dalam Tinimungan Tangon Kadazandusun (Himpunan Cerita Kadazandusun).

Dalam Himpunan Cerita Kadazandusun ini, terdapat beberapa cerita yang menggunakan nama watak yang sama seperti yang terdapat dalam "Yanakanak dan Rogon Gayo" dan "Yanakanak dan Lintagu" iaitu pengulangan nama watak Yanakanak manakala dalam cerita "Maki Yang Pemalas" dan "Oki dan Odou" yang menggunakan nama watak Oki dan Odou. Selain itu, watak Odou hampir sama sebutannya dengan watak Odu dalam cerita "Ikan Menjadi Manusia". Hal ini jelas memperlihatkan kepada kita bahawa tangon-tangon masyarakat Kadazandusun lebih terdedah dengan penggunaan nama watak secara tipikal.

Dalam tangon-tangon tersebut juga, terdapat beberapa cerita yang memiliki jalan cerita yang hampir sama iaitu "Maki yang Pemalas" dengan "Oki dan Odou". Dalam kesemua cerita tersebut boleh dilihat bahawa watak dalam cerita tersebut tidak berjalan sendirian malahan kebanyakannya cerita antara 
dua manusia, binatang, mahupun benda. Contohnya; Yanakanak om Rogon Gayo (watak manusia biasa dan manusia ganjil), Tutod om Kara (Binatang) dan banyak lagi yang lain. Dalam cerita tersebut juga, kebanyakannya dimulakan dengan perkataan 'I nopo di laid po'/'I pogulu po kaka' 'di nopo di guugulu po', 'Haro kaka di laid' (Pada suatu/Zaman dahulu).

Terdapat pelbagai watak dan perwatakan dalam Himpunan Cerita Kadazandusun ini. Namun demikian, pengkaji lebih memfokuskan kepada watak utama iaitu watak baik (protagonis) yang menjadi tunjang kepada cerita. Walau bagaimanapun, pengkaji turut membandingkan watak baik (protagonis) dengan watak jahat (antagonis) agar dapat membuat perbandingan antara dua watak bagi melihat lebih jelas lagi nilai yang dibawa oleh watak utama "hero". Kenyataan ini selaras dengan pendekatan yang akan digunakan oleh pengkaji iaitu pendekatan moral oleh Semi, 1993 yang menyatakan bahawa dengan melihat segi putih dan hitam dalam karya sastera secara serentak, kita mampu melihat isi sastera melalui watak dengan lebih jelas. Kita mengambil contoh cerita "Yanakanak" dan "Rogon Gayo" iaitu Yanakanak sebagai watak baik yang berjaya menumpaskan Rogon Gayo yang berperwatakan jahat kerana mencuri hasil jerat Yanakanak. Dalam cerita ini juga, terdapat cerita mempunyai watak Protagonis sahaja seperti cerita "Tebuan" yang lebih mengaitkan tentang cinta kasih.

\section{BATASAN KAJIAN}

Kajian ini memfokuskan perbincangan mengenai nilai pendidikan melalui watak dan perwatakan serta jalan cerita dalam lapan buah cerita rakyat Kadazandusun. Pemilihan lapan buah cerita adalah berdasarkan kesesuaian yang dimiliki oleh cerita tersebut dalam kajian ini.

\section{TAKRIF PENDIDIKAN}

Cerita rakyat (tangon-tangon) mempunyai fungsi universal sebagai medium hiburan di samping menjadi bahan mengajar dan mendidik kerana mempunyai peranan sebagai alat kawalan sosial dalam kehidupan seharian (Aripin, 1996). Pendidikan merupakan suatu aspek penting bagi setiap individu. Melalui pendidikan, manusia menjadikannya sebagai tumpuan dan harapan dalam usaha mengembangkan individu dan masyarakat. Menurut Mansur dan Muslich (2011), pendidikan juga merupakan suatu alat dalam memajukan peradaban, menjadikan masyarakat menikmati perkembangan serta menyedarkan generasi baharu agar bertindak terhadap pelbagai perkara bagi kepentingan. Walau bagaimanapun, kita dapat melihat pada masa kini bahawa dunia realiti sudah semakin tidak seiring dengan idealisme pendidikan.

Akhir-akhir ini masih terdapat banyak masalah yang menunjukkan kurangnya karakter baik yang dimiliki oleh murid. Semangat cinta dan pengabdian terhadap bangsa terkikis akibat pengaruh luar. Krisis ini kuncinya terletak pada sumber manusia dan kemajuan sesebuah bangsa pula terletak pada karakter bangsa tersebut. Jelaslah bahawa, karakter perlu dbentuk dan dibina secepat mungkin agar menghasilkan kualiti bangsa yang berkarakter baik (Rarasaning Satiangsih \& Lydia Lia Prayitno, 2011). Karakter ini boleh dibentuk seawal usia kanak-kanak kerana "melentur buluh, biarlah dari rebungnya". Pada peringkat usia muda lagi, kanak-kanak harus dibiasakan berada dalam lingkungan yang positif yang mencakup keluarga, sekolah dan masyarakat agar lahirnya generasi yang berkelakuan positif.

\section{TAKRIF TANGON-TANGON}

Tangon-tangon merupakan istilah dalam bahasa dusun yang membawa maksud cerita rakyat. Tangontangon ataupun cerita rakyat telah muncul sejak zaman nenek moyang lagi dan disampaikan secara lisan dari satu generasi ke generasi yang lain. Kebiasaannya, cerita rakyat adalah berbentuk tuturan yang berfungsi sebagai media dalam mengungkapkan perilaku berkaitan nilai-nilai dalam kehidupan yang sebati dengan kehidupan masyarakat. Dalam masyarakat Kadazandusun, sastera rakyat ini lahir dalam masyarakat Kadazandusun yang primitif dan bersifat universal. Cerita rakyat ataupun tangon-tangon yang disampaikan dalam bentuk lisan dan diwariskan secara turun-temurun mengalami tokok tambah (Minah Sintian, 2015). 
Dalam kutipan Kiefer (2010, p. 227) menyatakan bahawa "folktales have been defined as all forms or narrative, written or oral, which have come to be handed down through the years". Selain itu, unsur epik, balada, lagenda, mitos dan fabel juga termasuk dalam folktales. Kiefer (2010: 233-239) menyatakan ciri-ciri cerita rakyat iaitu cerita rakyat boleh dibandingkan dengan jenis cerita yang lain melalui alur, karakter, tema, motif dan jenisnya. Dalam cerita rakyat, struktur alurnya adalah sederhana, mengarah dan sentiasa berlaku pengulangan dari aspek tanggapan, nyanyian dan puisi. Dalam cerita rakyat, tidak dinyatakan secara spesifik waktu dan tempat berlakunya sesuatu peristiwa. Walaupun demikian, pencerita menyajikan sesuatu yang indah seperti pembukaan yang penuh konflik, karakter dan tempat yang menarik, dan kesimpulannya mengikuti klimaks yang sangat cepat dan jelas.

Menurut Danandjaya (2007, p. 2), cerita rakyat merupakan sebahagian daripada kebudayaan kolektif yang tersebar dan kemudiannya diwariskan secara turun-temurun di antara kolektif, baik secara tradisional dalam versi yang berbeza-beza, sama ada dalam bentuk lisan mahupun contoh yang diikuti oleh gerakan dan isyarat ataupun sebarang alat yang boleh membantu mengingat (memoric device). Folklore ataupun tangon-tangon berfungsi sebagai suatu medium dalam mewariskan adat istiadat dan norma-norma masyarakat pemiliknya khususnya untuk sastera lisan. Hal ini diperjelaskan lagi melalui pernyataan oleh Yanagita (Endraswara, 2009, p. 109) yang menyatakan bahawa folklore merupakan suatu "ajaran untuk hari esok" membawa erti suatu disiplin ilmu yang mampu membantu masyarakat Kadazandusun mengenal jati diri mereka sendiri serta mendalami sejarah yang wujud dalam kelompok masyarakat mereka.

\section{TAKRIFAN WATAK DAN PERWATAKAN}

Secara etimologi, karakter berasal dari bahasa Inggeris iaitu character yang bererti watak atau peranan. Penampilan watak dalam sesebuah cerita yang meyakinkan menarik pembaca sehingga mereka seolaholah berhadapan dengan sebenarnya (Jauhari, 2013, p. 161). Dalam pencirian watak, ia boleh merujuk rajah berikut:

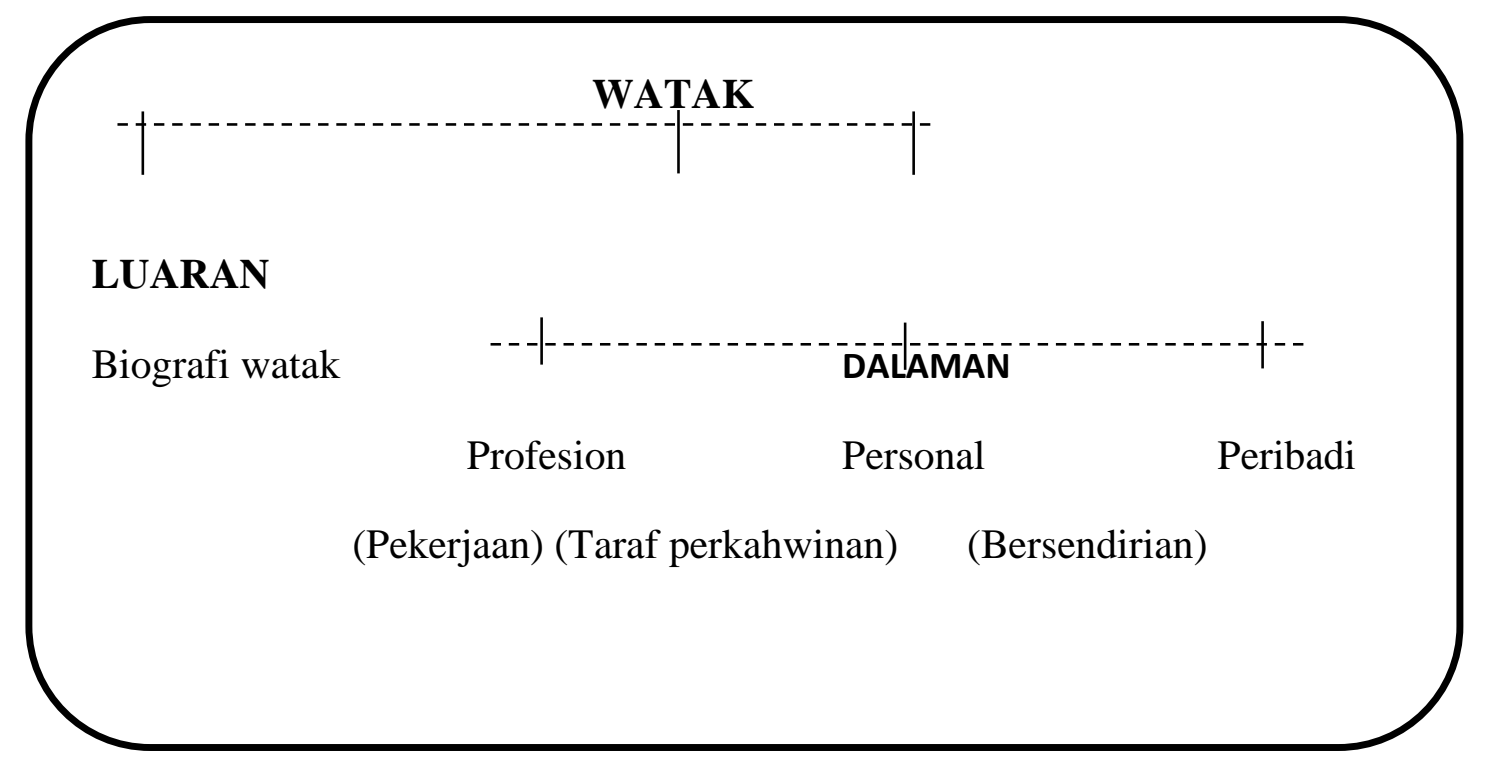

RAJAH 1Pencirian Watak

Keseluruhan watak utama atau 'hero' mengandungi sifat luaran dan dalaman seperti yang boleh dilihat dalam rajah di atas. Ciri-ciri tersebut merangkumi biografi watak, profesion personal dan peribadi. Watak protagonis ataupun selalunya dikenali sebagai watak 'hero' adalah watak yang bersifat dinamik dan menjadi watak utama dalam sesebuah cerita berbanding watak antagonis. Walaupun demikian, elemen 'hero' bukan hanya diterajui oleh watak protagonis sahaja, tetapi juga boleh dipegang oleh watak antagonis. Watak antagonis yang seringkali dianggap sebagai watak hitam adakalanya mempamerkan sifat yang baik dalam sesebuah cerita dan boleh menghulurkan bantuan kepada watak protagonis mahupun 
tritagonis. Hal ini demikian kerana, dalam sesebuah cerita, watak antagonis tidak semestinya sentiasa jahat namun masih memiliki sedikit nilai simpati dan empati (Othman Puteh, 1991, p. 23). Selain watak protagonis dan antagonis, terdapat juga suatu watak yang dikenali sebagai tritagonis iaitu watak sampingan ataupun pembantu/orang tengah bagi watak protagonis mahupun antagonis. Selain itu, watakwatak seperti watak bundar, watak pipih, watak dinamik, watak statik juga muncul dalam sesebuah cerita. Walaupun demikian, dalam kajian ini, pengkaji hanya menumpukan watak protagonis sebagai fokus utama dan watak antagonis sebagai bandingan.

\section{PENDEKATAN MORAL M. ATAR SEMI 1993}

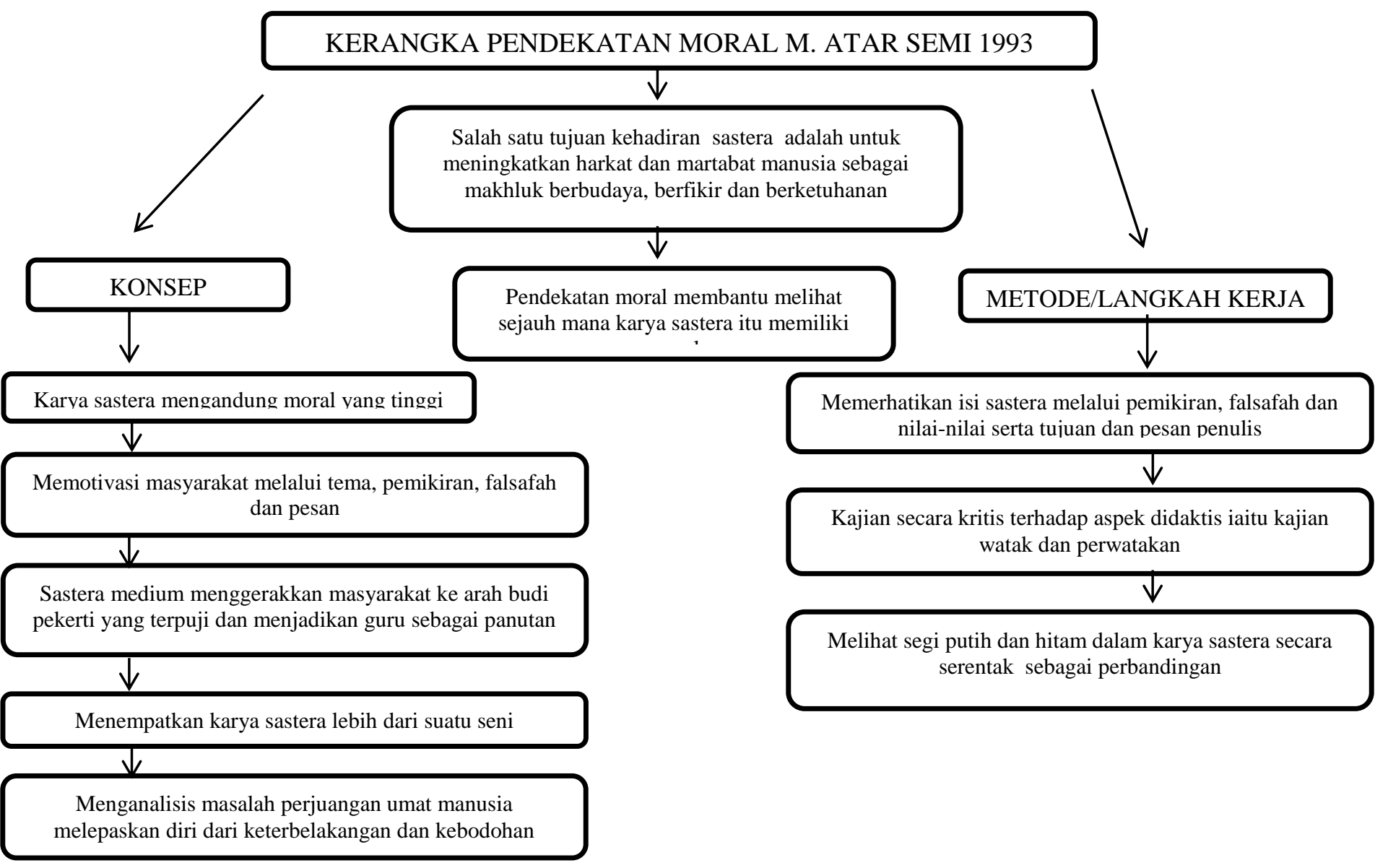

RAJAH 2 Pendekatan Moral Semi

Sastera seharusnya mampu menjadi wadah dalam menyampaikan idea-idea yang difkirkan dan dirasakan oleh sasterawan tentang kehidupan manusia. Dalam masyarakat Kadazandusun yang primitif, sastera lisan bersifat universal, membawa hiburan dan mampu menjadi medium dalam menyampaikan nasihat samada secara tersurat mahupun tersirat (Minah Sintian, 2015). Melalui rajah di atas, pengkaji menggunakan pendekatan moral yang dipelopori oleh M.Atar Semi, 1993 sebagai landasan utama dalam kajian ini. M.Atar Semi merupakan seorang ahli yang banyak membuat kajian tentang sastera. Antara kajian beliau ialah Metodologi Penelitian Sastera (1993), Anatomi Sastera (1998), Dasar-dasar keterampilan menulis (2007), Kritik Sastera dan banyak lagi.

Dalam pendekatan moral, Semi menyatakan bahawa terdapat beberapa konsep yang terlibat semasa meneliti sesebuah karya. Beliau menyatakan bahawa konsep pendekatan moral ialah karya sastera haruslah mengandungi nilai moral yang tinggi dan mampu memotivasi masyarakat melalui tema, pemikiran, falsafah dan pesan. Selain itu, beliau turut menyatakan konsep iaitu sastera merupakan medium dalam menggerakkan masyarakat ke arah budi pekerti yang terpuji dan menjadikan guru sebagai panutan. Konsep lain ialah karya sastera harus ditempatkan lebih daripada suatu seni dan dalam sastera 
berlakunya suatu proses menganalisis masalah perjuangan umat manusia dalam melepaskan diri dari keterbelakangan dan kebodohan.

M.Atar Semi (1993) menyatakan beberapa langkah kerja yang terdapat dalam pendekatan moral iaitu memerhatikan isi sastera melalui pemikiran, falsafah dan nilai-nilai serta matlamat dan juga mesej penulis, menjalankan suatu kajian kritis terhadap aspek didaktis iaitu kajian watak dan perwatakan. Selain itu, aspek putih dan hitam dalam karya sastera juga harus dinilai secara serentak untuk meneliti perbandingan dan memperhatikan masalah kesan dan juga tahap penerimaan pembaca.

\section{TEORI FORMASLITIK}

Dalam usaha menganalisis nilai dan fungsi sesuatu cerita (tangon-tangon), pengkaji menggunakan teori formalistik. Secara etimologi, formalistik merupakan suatu istilah yang berasal dari perkataan forma (latin) yang membawa maksud bentuk atau wujud. Definisi ini turut disokong oleh Mulyadi Mahmood (1993) dalam kenyataannya bahawa karya mempunyai dua elemen iaitu "formalistik" dan "ikonografi" yang disebut sebagai "bentuk" dan "isi" dan juga kebiasaannya dikenali sebagai "aturan" dan "makna". Kesemua elemen tersebut saling bersatu dalam membentuk sesebuah karya seni.

Dalam kajian ini, sebanyak 8 buah cerita rakyat telah diambil melalui "Tinimungan Tangon Kadazandusun" (Himpunan Cerita Kadazandusun). Cerita-cerita rakyat yang didokumentasikan merupakan suatu sumber dalam kajian tradisi lisan masyarakat Kadazandusun sehingga kini. Melihat pada teori Formalistik, Harun Jaafar (2003: 23) mengutarakan kenyataannya iaitu:

Karya sastera tidak ada kaitan dengan hal-hal lain dan pegangan itu mendorong aspek-aspek tema dan struktur iaitu plot, bentuk, latar, watak atau perwatakan dan kesemua aspek lainnya dikaji secara berasingan. Maka pendekatan formalistik merupakan aspek yang menghurai dan menjelaskan segala unsur yang terdapat dalam sesebuah karya sastera.

Ann Jefferson (1988) berpendapat bahawa formalistik merupakan suatu reaksi terhadap pendekatan sastera bersifat positif yang menganggap bahawa segala ilmu pengetahuan haruslah berasaskan fakta yang dapat diamati. Selain daripada itu, melalui kenyataan yang diperoleh dalam buku Harun Jaafar (2002:23) yang turut membahaskan mengenai teori ini menyokong bahawa pendekatan ini adalah berpandukan kepada perpaduan serta penyesuaian yang terjadi antara isi dan bentuk. Beliau juga menyatakan bahawa asas-asas pembinaan pendekatan teori formalistik ini telah dipelopori oleh Samuel Taylor Coleridge, Edgar Allen Poe dan Henry James. Tokoh-tokoh ini memberi pendapat mereka bahawa sesebuah hasil karya sastera memiliki unsur-unsur, ciri-ciri dan aspek yang membina. Aspek-aspek tersebut haruslah dikupas satu persatu agar mampu melihat lebih jelas lagi mengenai karya yang dikaji.

Penjelasan mengenai teori formalistik tersebut menjadi satu panduan kepada seseorang pengkaji sastera untuk menjalankan kajian analisis teks. Lazimnya, dalam cerita rakyat, bentuk dan isi yang seringkali dikaji ialah elemen plot, latar, watak perwatakan dan elemen-elemen formalistik. Adakalanya, elemen-elemen tersebut wujud dalam pelbagai bentuk. Maka, demi mendalami lagi nilai dan fungsi tangon-tangon, penelitian secara terperinci dijalankan oleh pengkaji menggunakan teori ini.

\section{KAEDAH KAJIAN}

Kajian ini dijalankan dengan menggunakan kajian analisis teks yang berasaskan Pendekatan Moral Semi, 1993 sebagai landasan utama dan Teori Formalistik sebagai teori sokongan. Selain itu, rujukan pustaka juga digunakan untuk membantu pengkaji lebih memahami isu kajian melalui sorotan literatur. Penganalisisan berfokuskan kepada nilai pendidikan melalui watak dan perwatakan serta jalan cerita dalam lapan buah cerita yang dipilih iaitu Yanakanak dan Rogon Gayo, Tebuan, Maki yang Pemalas, Rumpad Nipon , Oki dan Odou, Yanakanak dan Lintagu, Ikan Menjadi Manusia dan Bambarayon. Kelapan-lapan cerita ini dipilih kerana pengkaji mendapati cerita tersebut lebih menonjolkan nilai murni berbanding cerita yang lain. Sumber utama data ini diambil daripada Buku Himpunan Cerita Kadazandusun yang diterbitkan pada tahun 2016 hasil kerjasama Universiti Malaysia Sabah dengan Universiti Pendidikan Sultan Idris. Buku ini adalah hasil kutipan cerita oleh Minah Sintian dan Rosliah Kiting iaitu pensyarah minor Bahasa Kadazandusun Universiti Pendidikan Sultan Idris. 
JADUAL 1Ringkasan tangon-tangon yang dikaji (adaptasi teori formaslitik)

\begin{tabular}{|c|c|c|}
\hline TAJUK CERITA & WATAK & SINOPSIS \\
\hline Yanakanak om Rogon Gayo & Yanakanak dan Rogon Gayo & $\begin{array}{l}\text { Yanakanak menumpaskan Rogon } \\
\text { Gayo yang mencuri hasil jeratnya }\end{array}$ \\
\hline Tebuan & $\begin{array}{l}\text { Goroi, isteri, Ketua Rumah, } \\
\text { Tebuan }\end{array}$ & $\begin{array}{l}\text { Goroi berusaha mendapatkan } \\
\text { semula isteri kesayangannya yang } \\
\text { bertukar menjadi tebuan }\end{array}$ \\
\hline Maki yang Pemalas & Maki dan Odu & $\begin{array}{l}\text { Mengisahkan suami isteri yang } \\
\text { hidup dalam serba kekurangan. } \\
\text { Odu seorang isteri yang rajin } \\
\text { manakala Maki seorang suami } \\
\text { yang pemalas akhirnya memakan } \\
\text { dirinya sendiri. }\end{array}$ \\
\hline Rumpad Nipon & $\begin{array}{l}\text { Rumpad Nipon, Tomou Langou, } \\
\text { Pidot Songsong, Kambang Gapas, } \\
\text { ibu Kambang Gapas }\end{array}$ & $\begin{array}{l}\text { Rumpad Nipon membantu sebuah } \\
\text { keluarga yang miskin setelah niat } \\
\text { baiknya tidak diterima oleh Tomou } \\
\text { Langou dan Pidot Songsong }\end{array}$ \\
\hline Oki dan Odou & Oki dan Odou & $\begin{array}{l}\text { Pasangan suami isteri yang } \\
\text { berubah menjadi baik setelah si } \\
\text { suami (Oki) yang pemalas berubah } \\
\text { menjadi rajin setelah dikenakan } \\
\text { oleh isterinya. }\end{array}$ \\
\hline Yanakanak dan Lintagu & $\begin{array}{l}\text { Yanakanak, Ligot Liou, Sunsulit, } \\
\text { Lintagu }\end{array}$ & $\begin{array}{l}\text { Pertentangan sifat dua orang } \\
\text { pemuda akhirnya memakan diri } \\
\text { pemuda yang tamak dan iri hati } \\
\text { iaitu Lintagu. }\end{array}$ \\
\hline Ikan Menjadi Manusia & Laki, Odu, Akang, Raja, Ikan & $\begin{array}{l}\text { Kisah ikan yang dilahirkan oleh } \\
\text { manusia dan tidak diterima. } \\
\text { Namun, akhirnya ikan tersebutlah } \\
\text { yang mengubah kehidupan mereka. }\end{array}$ \\
\hline Bambarayon & $\begin{array}{l}\text { Petani 1, Petani 2, Petani } 3, \\
\text { pekebun, Bambarayon }\end{array}$ & $\begin{array}{l}\text { Bambarayon yang menyamar } \\
\text { sebagai seorang tua meminta } \\
\text { bantuan daripada beberapa orang } \\
\text { petani. Petani yang baik hati } \\
\text { akhirnya mendapat balasan yang } \\
\text { baik. }\end{array}$ \\
\hline
\end{tabular}

Sumber: Buku Tinimungan Tangon Kadazandusun, 2016 (Minah Sintian \& Rosliah Kiting)

\section{DAPATAN DAN PERBINCANGAN}

Buku Tinimungan Tangon Kadazandusun (Himpunan Cerita Kadazandusun) memuatkan sebanyak 23 buah cerita yang berjaya dikumpulkan dari pelbagai pelosok di negeri Sabah. Dalam buku tersebut, cerita dalam rumpun Kadazandusun merupakan cerita yang dipilih untuk diketengahkan. Melalui buku tersebut, banyak nilai pendidikan yang ditonjolkan melalui watak dan perwatakan serta jalan cerita dalam sesebuah cerita namun pengkaji hanya mengambil lapan buah cerita yang dilihat berseuaian dengan kajian yang akan dijalankan oleh pengkaji. Cerita-cerita ataupun tangon-tangon yang dipilih ialah 'Yanakanak dan Rogon Gayo', 'Tebuan', 'Maki yang Pemalas', 'Rumpad Nipon', 'Oki dan Odou', 'Yanakanak Dan Lintagu', 'Ikan dan Manusia' dan Bambarayon. Kesemua cerita ini menampilkan nilai murni serta pengajaran yang menarik melalui watak dan perwatakan yang dibawakan. 
Cerita 'Yanakanak dan Rogon Gayo' merupakan sebuah cerita mengenai seorang pemuda bernama Yanak-anak yang berjaya menumpaskan Rogon Gayo yang mahu mencuri hasil jeratnya. Jika kita menyelidik dengan lebih teliti, Yanakanak merupakan watak baik dalam cerita ini. Yanakanak sangat rajin melakukan aktiviti menjerat binatang sebagai sumber makanan. Hal ini digambarkan dalam ayat:

"I Yanakanak nopo nga aparu do momukasip"

"Yanakanak seorang yangrajin menjerat binatang"

Perwatakannya yang 'rajin' memberi gambaran kepada kita bahawa perbuatan rajin melakukan sesuatu aktiviti yang bermanfaat, kita akan mampu mendapatkan hasil. Contohnya seperti Yanakanak yang menjerat binatang untuk dijadikan lauk dan sumber makanan. Dalam cerita ini juga, Yanakanak mempunyai nilai simpati apabila dia tidak sampai hati membunuh Rogon Gayo yang merayu agar dilepaskan. Hal ini boleh digambarkan dalam ayat berikut:

\begin{abstract}
“Atukoi, Yanakanak kada oku po patayo!Mongoi kito po hilo’d walai ku om mamalasu kito po di sulung diti kasip nu om mibai' kito do makan.Kaangayai no I Yanakanak om tumboyoo' no dau ii pangangatan di Rogon Gayo".
\end{abstract}

"Wahai Yanakanak, janganlah engkau bunuh aku! Marilah ke rumahku dahulu dan merebus hasil jeratmu dan beradu makan. Yanakanak pun terpedaya lalu mengiakan ajakan Rogon Gayo".

Walaupun dalam ayat tersebut, Yanakanak sebenarnya terpedaya, namun jika melihat dalam aspek nilai pendidikan, Yanakanak mempunyai nilai simpati dan belas kasihan kerana sudi melepaskan Rogon Gayo serta tidak membunuhnya. Pengajaran yang boleh diperolehi melalui cerita ini ialah perbuatan mencuri merupakan salah satu perbuatan kurang bermoral yang akhirnya akan membawa padah.

Cerita yang kedua ialah "Tebuan" iaitu sebuah kisah pemuda berkahwin dengan seorang perempuan dari keturunan tebuan. Mereka berkahwin dan hidup bahagia namun terdapat perkara yang membuatkan si isteri berduka lalu kembali menjelma menjadi tebuan. Di sini, pengkaji mampu melihat nilai pendidikan yang wujud melalui watak si suami apabila dia berjuang untuk mendapatkan semula isteri kesayangannya itu. Nilai pendidikan yang diperoleh melalui perbuatan murni iaitu kasih sayang sungguh jelas dilihat melalui cerita tersebut;

"Mingihad podii daa I Goroi do mogodu nga amu no pinokinongoi di sawo dau. 'Poingkuro po nga ngoyon ku'I ia gusao', 'Kaka di Goroi do minimboros.Pomodoropi-doropi no yau om pamanau no guminusa di sawo dau”.

"Goroi menangis-nangis memujuk tetapi isterinya tidak mempedulikannya.' Bagaimana pun aku akan mengejar awak,' kata Goroi. Dia pun mengemaskan barang-barangnya lalu berjalan menyusuli isterinya".

Melalui ayat tersebut, dapat dilihat bahawa di suami mempunyai rasa bersalah kerana telah melakukan kesalahan yang melukakan isterinya. Kerana rasa bersalah dan juga perasaan cinta terhadap isterinya, maka Goroi mengambil keputusan untuk mendapatkan kembali isterinya itu. Nilai murni yang wujud dalam watak dan perwatakan Goroi ialah ikhlas, kasih sayang dan tabah. Nilai murni tersebut sekali gus menjadi suatu unsur pendidikan terhadap masyarakat bahawa cinta dan kasih sayang serta usaha yang tekal akhirnya akan membawa kepada keuntungan dan tercapainya apa yang kita hasratkan.

Cerita "Maki yang Pemalas" mengisahkan sepasang suami isteri yang dikenali sebagai Maki (si suami) dan Odu (si isteri) yang hidup dalam keadaan serba kekurangan. Isterinya seorang yang sangat rajin bekerja namun si suami pula seorang yang malas bekerja. Di sini, nilai murni yang mendidik masyarakat pembaca lebih ditonjolkan oleh watak Odu yang mempunyai perwatakan rajin ke kebun.

"I Odu nopo nga tondu di abagos kopio do mindahu. Ogumu no kaka o pounayan di Maki soira suhuon do mindahu om kuroyon podii, I Odu kasasari di mindahu mongoi pogium do taakanon" 
"Odu adalah seorang isteri yang sangat rajin ke kebun. Banyak alasan yang Maki berikan setiap kali disuruh ke kebun. Akhirnya Odu juga yang akan pergi mencari makanan”.

Melalui pernyataan yang diambil dari teks tersebut, dapat disimpulkan bahawa Odu seorang isteri yang rajin, penyayang dan taat kepada suami. Nilai murni yang terdapat dalam diri Odu itu juga menjadi punca mereka mampu meneruskan kehidupan dengan sumber rezeki yang dicari oleh Odu. Nilai murni ini juga mampu memberi nilai pendidikan kepada kita bahawa seseorang yang malas tidak akan mampu mendapatkan apa yang diinginkan kerana banyak perkara dimulakan dengan sikap rajin serta usaha yang kukuh.

Cerita seterusnya ialah "Rumpad Nipon" iaitu cerita menarik yang mengisahkan kisah dua beradik yang tinggal bersama di sebuah kampung. Watak tersebut ialah Tomou Langou dan Pidot Sonsong. Kedua watak ini merupakan watak antagonis iaitu sangat kedekut dengan hasil mereka dan tidak mempedulikan nasib orang lain yang hidup melarat. Secara fizikal, mereka berperwatakan sebagai jejaka yang kuat, dan amat rajin bekerja. Walaupun mereka watak yang kurang baik dalam cerita ini namun mereka masih memegang nilai murni yang mendidik masyarakat pembaca iaitu rajin bekerja. Watak utama dalam cerita ini ialah Rumpad Nipon iaitu jelmaan Bambarayon (semangat padi) yang menjelma menjadi manusia dan berfizikal hodoh iaitu mempunyai gigi berlapis. Watak Rumpad Nipon merupakan watak Protagonis kerana telah membantu keluarga Kambang Gapas yang miskin.Nilai membantu merupakan nilai murni yang dipegang oleh Rumpad Nipon. Bagi Watak Kambang Gapas dan ibunya, mereka memegang watak sebagai sebuah keluarga yang miskin tetapi baik hati. Nilai baik hati yang dimiliki oleh keluarga ini akhirnya membawa kepada rezeki yang berlimpah apabila Rumpad Nipon iaitu jelmaan semangat Bambarayon memberikan mereka padi dan beras yang berlimpah. Dalam cerita ini, nilai pendidikan yang wujud adalah kita tidak seharusnya tamak dalam berkongsi keuntungan yang kita ada kepada orang lain kerana di akhirnya kita juga akan memerlukan bantuan orang tersebut suatu hari kelak.

"Oki dan Odou" merupakan cerita yang hampir sama dengan cerita "Maki yang Pemalas". Dalam cerita ini, juga mengisahkan tentang sepasang suami isteri yang tinggal di pinggir sebuah kampung di Daerah Kinabatangan. Watak Odou dalam cerita ini ialah seorang wanita yang rajin dan cergas ketika melakukan sesuatu kerja. Odou juga berperwatakan bijak kerana berjaya mengenakan suaminya Oki sehingga suaminya berubah menjadi rajin. Oki pula merupakan seorang suami yang malas bekerja, suka menipu dan bercita-cita tinggi namun tidak melaksanakannya. Melalui watak Oki, dapat dijelaskan bahawa sifatnya yang suka berangan-angan namun tidak melakukan apa-apa terhadap angan-angan tersebut hanya akan terkubur begitu sahaja tanpa hasil yang diinginkan.Hal ini boleh dilihat melalui ayat;

“Tikid tadau nga miagal I' o kowowoyoo' di Oki. Miguli-guli no I Oki do mongoi do hilo id pongumaan dau do gisom do sombulan nga au po mangangat I Oki di Odou do mooi intong do tagad dau”.

"Saban hari, begitulah sikap Oki yang hanya berangan-angan tetapi tidak melakukan sebarang pekerjaan.Walalupun telah hampir sebulan lamanya Oki berulang-alik ke kawasan penanaman padi itu, tetapi belum ada lagi hasil kerja yang dilihat oleh Odou".

Cerita ini turut mendidik kita bahawa kebijaksanaan juga mampu mengubah seseorang yang lain untuk menjadi lebih baik. Sifat sabar juga mampu menjadikan segala perkara ataupun masalah boleh diselesaikan dengan baik.

Cerita seterusnya ialah "Yanakanak dan Lintagu" yang mengisahkan tentang pertentangan sifat dua orang pemuda. Dalam cerita ini, Yanakanak merupakan watak yang berperwatakan rajin, menghormati orang tua dan budiman manakala Lintagu pula merupakan seorang yang mempunyai sikap malas, iri hati dan juga terburu-buru. Sikapnya yang sedemikian akhirnya membawa padah kepada dirinya sendiri. Sifat rajin dan taat kepada ibu bapa Yanakanak boleh dilihat melalui petikan;

"Insan o tadau, sinuhu isio di molohing dau do mooi pokisuduon. Ongoi no Yanakanak pokisuduon miampai minamabo' do waked di agayo”.

"Suatu hari Yanakanak telah disuruh oleh ibunya mencari kayu api. Pergilah Yanakanak mencari kayu api dengan menggalas sebuah wakid yang besar". 
Perwatakannya yang menghormati orang tua juga dilihat melalui petikan;

"Muli ko nopo oi ondu, igitan no iti tobubut do patahakon ku dika nga sorohon no, korikot po'd hilo id walai om sukaban nogi. Kada no pingkowili-wili id dalan. 'pounsikou Odu,' ka di Yanakanak do suminimbar, om ibok no isio o minamanau do muli. Id tindalanon, ати no kuminowili I Yanakank do gisom nokorikot do hiri id walai".

" $\mathrm{Cu}$, sebelum pulang bawalah uncang ini tetapi ingatlah, sampai di rumah baharulah dibuka. Selalin itu, janganlah menoleh ke belakang,” Pesan nenek kepada Yanakanak. 'Terima kasih nek,' kata Yanakanak lalu beredar pulang. Sepanjang jalan pulang, Yanakanak tidak sekalikali menoleh ke belakang".

Cerita "Ikan Menjadi Manusia" merupakan cerita versi Kimaragang yang mengisahkan kisah sepasang suami isiteri iaitu Laki dan Odu yang hidup serba kekurangan di sebuah negeri yang diperintah oleh seorang Raja. Odu telah melahirkan anak iaitu seekor ikan.Laki yang kecewa berhasrat hendak membuang ikan tersebut. Ikan itu tidak dibuang kerana ibunya Odu sangat menyayangi darah dagingnya sendiri. Nilai kasih sayang itu mengajar kita untuk menerima apapun keadaan seseorang yang hadir dalam kehidupan kita. Ikan tersebut menjadi dewasa dan menyuruh kedua orang tuanya untuk pergi berjumpa dengan Raja. Raja memiliki sifat murah hati kerana telah memberikan apa yang diminta oleh Odu. Sifat kepercayaan Odu terhadap anaknya itu Akang (seekor ikan) akhirnya telah mengubah nasib hidup mereka yang miskin menjadi lebih baik.

Cerita seterusnya ialah Bambarayon yang diambil daripada versi cerita Kampung Magatang Keningau. Cerita ini mengisahkan Bambarayon (semangat padi) yang menyamar menjadi manusia dan lalu di kawasan pertanian untuk meminta sedikit hasil tanaman daripada para petani. Petani pertama yang dijumpainya sehingganalah petani yang ketiga mengahalaunya dan tidak memberikan hasil kepada Bambarayon. Mereka sangat kedekut. Apabila akhirnya Bambarayon melalui tempat seorang pekebun buah-buahan yang baik hati, dia memberi Bambarayon apa-apa sahaja yang diminta meskipun belum ada hasil yang dikeluarkan oleh tanamannya. Kemurahan hati yang dibawa oleh watak Pekebun buah-buahan akhirnya dibalas baik oleh Bambarayaon. Petani yang kedekut tadi pula kehilangan padi mereka akibat dimakan oleh burung pipit.

\section{KESIMPULAN}

Watak dan perwatakan dalam sesebuah cerita yang membawa nilai murni mampu menarik para pembaca untuk mendalami watak dan seterusnya mampu mendidik para pembaca untuk berperilaku baik berbanding perilaku yang kurang baik. Pengaplikasian Pendekatan moral membantu pengkaji untuk membuat kajian menggunakan landasan yang tertuju. Semi mengatakan bahawa segi hitam dan segi putih watak dan perwatakan harus diambil kira apabila menganalisis sesebuah karya Sastera.

Secara keseluruhannya, tangon-tangon masyarakat Kadazandusun membawa pelbagai nilai murni yang menjadi tunjang nilai pendidikan yang berguna kepada setiap masyarakat. Dalam aspek pembentukan karakter pula, seperti yang kita tahu, negara Malaysia sedang mengorak langkah drastik dalam mencapai status "Negara Maju" menjelang 2020. Dalam mewujudkan modal insan berkualiti, penghasilan individu yang mempunyai jati diri kukuh, berketerampilan, berkeperibadian mulia, berpengetahuan dan berkemahiran tinggi bagi mengisi keperluan negara maju sangat penting (Mohamad Khairi Haji Othman, 2016). Dalam melahirkan modal insan berkualiti, aspek pembentukan karakter sangat pentingsama ada secara lisan mahupun tulisan (Vivian Lindayani, 2013). Pendidikan merupakan suatu proses membimbing atau memimpin secara sedar oleh para pendidik terhadap perkembangan jasmani dan rohani anak didik dalam membentuk keperibadian pelajar (Ahmad D. Marimba 1962).

\section{RUJUKAN}

Abdul Halim Bin Bandan. (1999). Cerita rakyat kaum bajau semporna, Sabah: suatu analisis citra masyarakat. Bangi: Universiti Putra Malaysia. 
Ahmad Faizal Kp Mohamed Yusup. (2002). Keluar dari tempurung: pembentukan diri kearah cemerlang. Kuala Lumpur: Utusan Publications \& Distributors Sdn. Bhd.

Ahmad Marzuki Ismail. (2007). Jati diri pelajar: interaksi dan amalannya. Selangor: Karisma Publications Sdn. Bhd.

Athur Asa Berger. (2010). Pengantar semiotika: tanda-tanda dalam kebudayaan kontemporer. Yogyakarta: Tiara Wacana.

Bambang Sumintono, Lokman Mohd Tahir, Mohd Anuar Abdul Rahman. (2012). Moral education in Malaysia: problems and implimentation in Schools, Journal of Character Education, 14-22.

Drs. P. Hariyono \& Dr. Ir. P.Wiryono, SJ. (1996). Pemahaman konstektual: tentang ilmu budaya dasar. Yogyakarta: Kanisius.

Dr. P.M. Laksono. (1999). Teori budaya. Yogyakarta: Pustaka Pelajar.

Dewi Rukmini. (2009). Cerita rakyat kabupaten sragen: suatu kajian struktural dan nilai edukatif. Surakarta: Universiti Sebelas Maret.

Dr. Hj. Esti Esmawati, M.Pd. (2013). Pengajaran sastra. Yogyakarta: Penerbit Ombak.

Eka Sapti C, Nur Cholimah, Martha C. (2014). Pelatihan pengenalan karakter untuk anak usia dini melalui cerita rakyat budaya lokal bagi pendidik PAUD non formal TPA/KB/SPS se-kecamatan sleman. Yogyakarta: Prodi PGPAUD Kampus Karangmalang UNY.

Horton, Paul B., DAN Chester L. Hunt. (1991). Sosiologi, Jilid 1. (Terjemahan Aminuddin Ram dan Tita Sobari). Jakarta: Penerbit Erlangga.

Haron Daud. (2001). Mantera Melayu: analisis pemikiran. Pulau Pinang: Universiti Sains Malaysia.

Henry Bating. (2014). Karya cerpen kadazandusun dalam konteks kokurikulum. Research in Social and Behavioral Sciences, 134, 350-363.

Jefferson, Ann. (1988). "Formalisme rusia" dalam teori kesusateraan moden: pengenalan secara perbandingan. (Terjemahan edisi Malaysia oleh Mokhtar Ahmad). Kuala Lumpur: Dewan Bahasa dan Pustaka Kementerian Pendidikan Malaysia.

Julita @ Norjietta Taisin. (2014). Sudawil: analisi dari aspek makna. Sabah: Universiti Malaysia Sabah.

Kamal Abd. Manaf. (1996). Manusia dan personaliti: membentuk insan yang sempurna. Kuala Lumpur: Utusan Publications \& Distributors Sdn Bhd.

Mat Jani Hassan. (1998). Kajian teks sastera STPM: warna sari sastera melayu tradisional prosa dan puisi. Selangor: Addison Wesley Longman Malaysia Sdn. Bhd.

Mohd Dahlan A. Malek \& Ida Shafinaz Mohamed Kamil. (2010). Jenayah dan masalah sosial di kalangan remaja: cabaran dan realiti dunia siber. Sabah:Universiti Malaysia Sabah.

Mohd. Rashid Md Idris, Siti Khariah Mohd Zubir, Abdullah Yusof. (2010). Nilai estetik dan intelek dalam pantun. Tanjung Malim: Emeritus Publications.

Misran Rokimin. (2013). Kritikan sastera remaja: teori dan aplikasi. Bangi: Universiti Kebangsaan Malaysia.

Mohd Fahmi Ismail, Salmah Jan Noor Muhammad, Mohd Sharifudin Yusop. (2015). International Journal of Language Education and Applied Linguistics (IJLEAL),03 (2015), 91-100.

Minah Sintian \& Rosliah Kiting. (2016). Tinimungan tangon kadazandusun: himpunan cerita kadazandusun. Perak: Pejabat Karang Mengarang Universiti Pendidikan Sultan Idris.

Noriah Taslim. (2010). Lisan dan tulisan: teks dan budaya. Selangor: Dewan Bahasa dan Pustaka.

Ni Putu Parmini. (2015). Eksistensi cerita rakyat dalam pendidikan karakter siswa SD di Ubud.Jurnal Kajian Bali, Vol. 5, No.2, November 2015, 1-10.

Rarasaning Satianingsih \& Lydia Lia Prayitno. (2011). Membangun karakter berbasis cerita. Surabaya:Universiti PGRI Adi Buana Surabaya.

Rosliah Kiting. (2013). Unsur-unsur sejarah dalam sudawil (pantun) kadazandusun. TanjungMalim: Universiti Pendidikan Sultan Idris.

Shahnon Ahmad. (1991). Sastera sebagai seismografi kehidupan. Kuala Lumpur: Dewan Bahasa \& Pustaka.

Soemardjan, Selo. (1997). Kemiskinan: suatu pandangan sosiologi. Jurnal Sosiologi Indonesia, No.2, September 1997, 3-4.

Suraya Sintang. (2003). Penganutan agama Islam dan Kristian di kalangan masyarakat Kadazandusun Sabah.

Sohaimi Abdul Aziz. (2004). Novel dalam kritikan. Pulau Pinang: Penerbit Universiti Sains Malaysia.

Suwardi Endraswara.(2005). Tradisi lisan Jawa: warisan abadi budaya leluhur. Yogyakarta: Penerbit Narasi.

Siti Saudah. (2014). Bahasa positif sebagai sarana pengembangan pendidikan moral anak. Research Institut Sains dan Teknologi 'AKPRIND', 14(1), 67-84.

Wan Yusof Hassan \& Siti Hadiah Hj. Abd.Mutalib. (1989). Cerita rakyat Sabah. Kuala Lumpur: Dewan Bahasa dan Pustaka. 